\title{
latrogenic ureteral injury after gynecological surgery
}

\author{
Ariane P. Smith, MD; Amelie Bazinet, MD; Daniel Liberman, MD, MSc
}

Division of Urology, Department of Surgery, Centre Hospitalier de I'Université de Montréal, Montreal, QC, Canada

Cite as: Can Urol Assoc J 2019;13(6Supp14):S51-5. http://dx.doi.org/10.5489/cuai.5936

\section{Abstract}

latrogenic ureteral injury can occur in many different settings, however, the majority occur in the context of gynecological procedures. We present a case of a ureteral injury during vaginal hysterectomy for severe pelvic organ prolapse. We provide a discussion on the diagnosis and management of ureteral injury after gynecological surgery. In addition, we compare and contrast the American Urologic Association and European Association of Urology guidelines and offer a short, concise algorithm on the management of all type of ureteral injuries.

\section{Epidemiology and prevention}

latrogenic ureteral injury can occur in many different settings. Colorectal surgeries and vascular abdominal surgeries are known to put ureters at risk of trauma. However, the majority of iatrogenic ureteral injuries occur during gynecological procedures (52-82\%). The total incidence of ureteral trauma after gynecological surgery is reported to be between $0.5 \%$ and $1.5 \% .^{1,2}$

In high-risk procedures, prophylactic ureteral stents can be used according to the European Association of Urology (EAU) guidelines on urological trauma. ${ }^{3}$ However, the efficacy of ureteral stenting remains controversial. A randomized controlled trial comparing preoperative stents in major gynecological procedures found no difference in injury rate between those with or without prophylactic stenting. ${ }^{4}$ Some authors have also suggested that preoperative stenting may increase the risk of ureteral injury by moving the ureter away from its normal anatomical location and reducing its mobility. ${ }^{5}$ The use of trans-illuminating stents has also been suggested to help identify the ureter during laparoscopy; however, their use has been limited by costs, as well as by the additional equipment required. ${ }^{6}$

In all, the EAU guidelines state that prophylactic doubleJ stenting can help identify and facilitate dissection of the ureters but do not reduce risk of injury. Conversely, the American Urological Association (AUA) guidelines on urotrauma do not address prevention of ureteral injuries. ${ }^{3,7}$

\section{Case}

A 56-year-old multiparous, post-menopausal female underwent vaginal hysterectomy and repairs for severe uterine prolapse. Suspension of the apex of the vaginal vault was achieved with vaginal uterosacral colpopexy. Intraoperative cystoscopy ruled out bladder perforation, and ejection of urine from bilateral ureteric orifices was confirmed. A course of antibiotics was administered before and continued for three days after the surgery. She was discharged well three days postoperatively.

The patient remained symptom-free until the third week, where she developed left flank pain and urinary vaginal discharge. Speculum exam demonstrated significant vaginal discharge at the posterior fornix. Cystoscopic examination was normal. Computed tomography (CT) urogram revealed a distal ureteral stricture and ureterovaginal fistula. These findings were compatible with a ureteral injury most likely during vaginal vault suspension (Fig. 1).

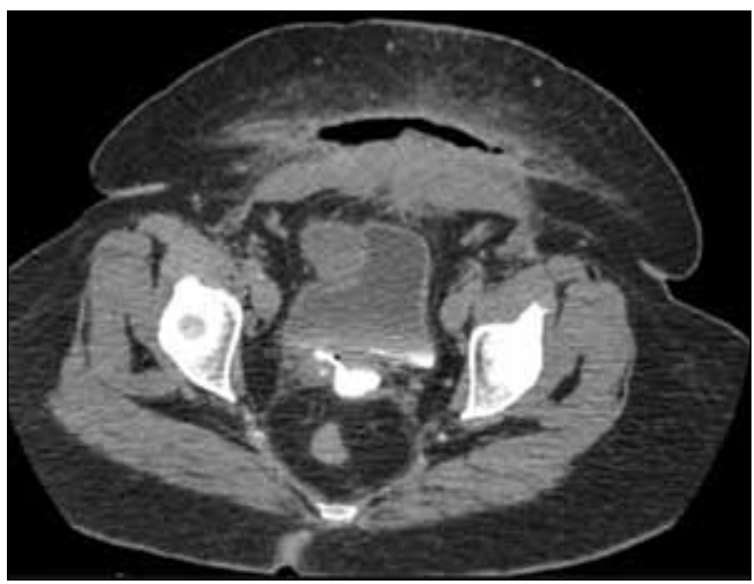

Fig. 1. Computed tomography (CT) urogram demonstrates a distal ureteral stricture and uretero-vaginal fistula. 


\section{Diagnosis}

Ureteral injury is detected intraoperatively in as low as $8.6 \%$ of cases, compared to up to $70 \%$ in the postoperative period. ${ }^{8}$ Perioperative cystoscopy, used to document the presence of bilateral ureteral efflux, is controversial and success rates vary greatly in the literature; ${ }^{9}$ however, detection rates can be improved by combining it with the use of $5-10 \mathrm{~mL}$ of intravenous indigo carmine during intraoperative cystoscopy. The AUA and EAU mention that the use of intravenous or intra-ureteral dyes, such as methylene blue, indigo carmine, and retrograde pyelography, can be useful..$^{3,7}$

Ureteral trauma must be suspected in the postoperative period when facing upper urinary tract obstruction, urinary fistulae, or sepsis. Other clinical signs include delayed flank pain, urinary incontinence, vaginal or drain urinary leakage, hematuria, fever, uremia, or urinoma..$^{10}$

When ureteral trauma is suspected postoperatively, CT scan with delayed excretory phase is considered the best diagnostic tool according to the EAU and AUA., ${ }^{3,7}$ Findings on CT urogram include: ureteral contrast extravasation, urinoma, hydronephrosis, and ascites. Retrograde or antegrade pyelography are also sensitive radiographic tests for ureteral injury, while also allowing simultaneous placement of a stent.

\section{Management}

\section{Immediate vs. delayed repair}

The EAU and AUA state that surgeons may address ureteral injury at the time of initial surgery in stable patients. In unstable patients or those sustaining a significant colon injury requiring colectomy, ureteral ligation and urinary derivation with percutaneous nephrostomy tube is recommended. Definitive repair should also be postponed. ${ }^{3,7}$

Early repair is controversial but may be possible if the injury is discovered within the first 72 hours postoperatively. After this period, urinary diversion with ureteral stent, nephrostomy, or both, followed by a delayed repair is suggested after a period of six weeks to avoid the inflammatory phase..$^{11,12}$

Authors advocating for delayed repair suggest that a double-J stent in itself can negate further repair in $5-50 \%$ of cases. ${ }^{1,13}$ Failure to place the stent can be secondary to complete obstruction of the ureter or a significant defect. In addition to ureteral stenting, it has also been suggested that percutaneous drainage may increase the rate of healing in patients with a history of pelvic radiotherapy or previous ureteral or pelvic surgeries. ${ }^{14}$

In cases of ureterovaginal fistula with late presentation of ureteral injury, stenting has been described with a success rate ranging between $64 \%$ and $76 \%$. In cases of persistent fistula, ureteral reimplantation was pursued and increased the rate of success to almost $100 \%$, with or without the need of Psoas hitch/Boari flap. ${ }^{7}$ This strategy is supported by both the EAU and AUA. ${ }^{3,7}$

Depending on the type and length of the injury, spontaneous ureteral repair after stenting may occur in up to $75 \%$ of patients. Considering this relatively high success rate, delayed surgical repair should only be considered in cases of persistent leakage or stricture..$^{1,13}$

EAU guidelines suggest that primary surgical repair is indicated in cases of ureteral stent failure or in cases of delayed diagnosis; ${ }^{3}$ however, ureteral strictures may occur secondary to trauma and can initially be managed with endoscopic procedures. Balloon dilatation appears to be an appropriate first step in the treatment of iatrogenic strictures of less than three months, with a success rate of $85 \% .{ }^{15}$ Moreover, distal strictures have a better response to balloon dilatation than mid or proximal ones. In cases of failed balloon dilatation, endoureterotomy of the stricture can be considered by the surgeon, with an average success rate of about $80 \%$. However, significant morbidity, such as hemorrhage, has been documented with this treatment option. ${ }^{16}$

The European and American guidelines adopt very similar approaches regarding the timing at which to repair ureteral trauma. Effectively, primary repair should be attempted intraoperatively in stable patients. Attempt at ureteral stenting should be done in cases of partial ureteral injury or distal ureteral fistulae. Finally, in cases of delayed diagnosis, percutaneous nephrostomy tube should be placed, considering the low rate of successful retrograde stenting., 3,7

\section{Surgical repair}

Management of ureteral injury depends on the nature, severity, and location of the trauma. General principles when repairing the ureter are important to ensure better cure rates, while avoiding complications. These principles include debridement, spatulation of ureteral ends, watertight mucosa-to-mucosa anastomosis, use of absorbable sutures, internal stenting, and isolation of the injury with peritoneum or an omental patch. The use of a ureteral stent after partial or total laceration repair is also recommended to reduce complications and achieve better outcomes. ${ }^{3,7}$

\section{Proximal ureteral injury}

Options for proximal injury include uretereoureterostomy, ureterocalycostomy, transureteroureterostomy, intestinal transposition, and auto-transplant. ${ }^{3}$ Ureteroureterostomy is the preferred option for lesions less than $3 \mathrm{~cm}$ if a tensionfree anastomosis can be performed. ${ }^{10}$ When access to renal pelvis is compromised by fibrosis or ischemia, lower pole ureterocalicostomy is advised. ${ }^{17}$ 
For longer ureteral substance loss, transureteroureterostomy may be indicated. ${ }^{3}$ The donor ureter should be passed through the sigmoid's mesentery with careful mobilization of the mesoureter in order not to compromise the ureteral blood supply. Limited mobilization of the recipient ureter is also important to prevent ischemia. The donor ureter is then spatulated on approximately $2 \mathrm{~cm}$ and an end-to-side anastomosis is performed. ${ }^{18}$ Contraindications to this procedure include: short donor ureteral length as well as pathology of the recipient ureter, including: stones, urothelial or pelvic cancer, retroperitoneal fibrosis, and previous pelvic radiation. Postoperative complications are experienced in up to $24 \%$ of patients, including urinary leak $(10 \%)$, stenosis requiring a re-intervention $(10 \%)$, and infection (5\%). ${ }^{19}$

The use of intestinal transposition, mostly using ileal segment, is another option to manage ureteral trauma, particularly in cases of extensive injury. High success rate and low complications have been reported, with only $3 \%$ anastomotic strictures and $6 \%$ fistula. ${ }^{20}$ Transposition using colon or appendix has been reported; however, ileal transposition is generally considered very reliable. ${ }^{21}$

A few cases of ureteral strictures or injuries repair using buccal mucosa graft have been described in the contemporary literature, with the first case initially described in 1999. The use of buccal mucosa graft in long or complex upperand mid-ureteral injuries may be an interesting alternative to avoid bowel interposition in case of impossible ureteroureterostomy. The use of buccal mucosa also avoids extensive ureteral dissection, therefore limiting ureter devascularization. Moreover, this procedure does not preclude the possibility of a more definitive procedure in case of graft failure. The success rates of buccal graft ureteroplasty, have been shown to be as high as $92 \%$, with a median followup of 22 months. ${ }^{22}$

Finally, auto-transplantation may be considered for very extensive injuries or refractory cases. ${ }^{3}$ If considered perioperatively during the primary injury, the ureter should be ligated and urine diverted with a nephrostomy tube. An elective procedure must be planned afterwards. Best results are achieved when the procedure is performed by a surgeon with experience in transplantation procedures. Therefore, preoperative consultation may be advisable. ${ }^{23}$

Thus, primary ureteroureterostomy with ureteral stenting is the EAU and AUA's preferred approach regarding proximal ureteral injuries. The EAU mentions the possibility of ureterocalycostomy or transureteroureterostomy in case of moderately extensive injury. Both also describe ileal transposition and auto-trasplantation as solutions for proximal injury, but mostly in case of seriously injured ureter., ${ }^{3,7}$

\section{Distal ureteral injury}

Most iatrogenic injury occurs in the distal ureter. Since distal injuries are often associated with ligation of internal iliac artery branches, this part of the ureter is at higher risk of suffering from ischemia. ${ }^{24}$ Thus, the EAU and AUA advocate for re-implantation and stent placement over ureteroureterostomy for lesions located distal to the iliac vessels.,

When tension-free re-implantation is impossible, the surgeon may use a Psoas hitch or a Boari flap to bridge the deficit. Success rates reach up to $97 \% .{ }^{24}$ A Boari flap can be used to bridge longer gaps for mid- to distal-ureteral injuries, allowing a tension-free ureteroneocystostomy. For longer deficits, the Boari flap can be combined with a Psoas hitch. Success rate of this technique varies between $81 \%$ and $87 \% .^{25}$

In recent years, minimally invasive techniques have become increasingly popular as an alternative to open surgeries. While laparoscopic repair of ureteral injuries has been largely reported since the 90s, robot-assisted surgery has emerged as a minimally invasive alternative for treatment of ureteral injuries. Robot-assisted ureteroureterostomy and re-implantation have been described in case series with a success rate of more than $94 \%$ and a low complication rate. According to the literature, there is no difference in terms of complication rates between open and robot-assisted ureteral repair. However, length of stay and blood loss are significantly lower with the robotic approach. ${ }^{26}$ Thus, repair of distal ureteral injuries using laparoscopy or robotic surgery is considered an acceptable treatment option. There is currently no long-term data to formulate guidelines specifically addressing the minimally invasive approach.

In all, both the EAU and AUA recommend ureteroneocystostomy with or without Psoas hitch/Boari flap in cases of distal ureteral trauma. ${ }^{3,7}$

\section{Followup}

Ureteral stenting is often used in the context of ureteral injury whether diagnosed early or late. No specific recommendations exist on the optimal stenting duration. Nevertheless, there is a tendency to leave the stent in place for a minimum of six weeks. ${ }^{21}$ Indeed, some authors have demonstrated that the ureteral wall can completely regenerate within 3-6 weeks following full-thickness ureteral incision. ${ }^{27}$ However, various treatment suggestions have been formulated in the literature according to the type of injury. In cases of ureteral contusion with a leak, percutaneous nephrostomy and ureteral stenting for a minimum of six weeks proved to be efficient in $83-88 \%$ of cases. ${ }^{28}$ Depending on the type of injury and degree of tissue damage, ureteral stents can be kept longer. For instance, some will advise removal of ureteral stents 12 days after ureteral reimplantation but some will suggest keeping the stent two months in case of ligation injury in order for tissues to heal appropriately. ${ }^{5}$

Followup after ureteral injury and repair can be handled in different ways. Some propose the use of a CT urogram to 
demonstrate the absence of any anastomotic or ureteral leak 2-3 weeks after surgery, before removal of the stent. Longterm followup with CT urogram, intravenous pyelography, renal ultrasound, and serum creatinine can be done and 3-6 months and repeated at 12 months in order to avoid late strictures or complication. ${ }^{29}$ Others will advocate for a minimum of two years of followup. ${ }^{5}$

An algorithm to summarize the management of iatrogenic ureteral injuries is included in Fig. 2.

\section{Case followup}

Our patient mentioned above developed a uretero-vaginal fistula after vaginal hysterectomy in the context of severe pelvic organ prolapse. Distal ureteral injury occurred most likely during suspension of the vaginal vault using a uterosacral colpopexy. Retrograde ureteral stenting was first attempted but failed due to injury and severe obstruction. After percutaneous nephrostomy placement, the patient eventually underwent an open uereteroneocystostomy at three months.

\section{Complications}

The potential impact of high-grade pelvic organ prolapse on the upper urinary tract is known. Indeed, obstructive uropathy is reported in $5 \%$ of first-degree prolapse, but may be as high as $40 \%$ in procidentia. Hydronephrosis associated with obstructive uropathy may lead to a tortuous ureter and place the ureter in a non-anatomical position that may increase the risk of injury during prolapse repair. Limitation of injury can be achieved by intimate knowledge of the pelvic anatomy, careful visualization and palpation of the ureter, and in some instance, by prophylactic ureteral stent placement. ${ }^{30}$ However, results from previous studies have not demonstrated significant differences in the rates of ureteral injury when a prophylatic stent is used. ${ }^{4}$

Fistulas are one of the most feared complications in gynecological surgery and more than $50 \%$ of them occur after hysterectomy for benign pathology. Fistulae should be suspected when patients present with continuous urinary leakage after surgery. Other presentations include fever, abdominal pain, hydronephrosis, ileus, and hematuria. Although they usually present rapidly after the surgery, $10-15 \%$ of fistulae present after 3-4 weeks and even later. When suspected, CT scan, excretory urography, retrograde pyelography, voiding cystourethrography, or magnetic resonance may be useful diagnostic tools.

Uterosacral ligament suspension is associated with a rate of ureteral injury between $1.8 \%$ and $10.9 \%{ }^{; 0}$ however, most associated complications are obstructive in nature, while fistulae are rare. ${ }^{31}$ Moreover, the vaginal approach is associated with a higher rate of ureteral injury than the abdominal approach. ${ }^{32}$

\section{Conclusion}

Post-hysterectomy ureteral injury is not uncommon. Early diagnosis and treatment have been shown to reduce morbidity. Primary repair should be attempted intraoperatively in stable patients. Early intervention with endourological procedures can improve outcomes. Finally, in cases of delayed diagnosis, percutaneous nephrostomy tube should be placed, followed by ureteroneocystostomy.

Fig. 2. Management algorithm for iatrogenic ureteral injuries. interp: interposition; perc: percutaneous; re-implant: re-implantation; trans-u: transureteroureterostomy; U-C: ureterocalycostomy; U-U: ureteroureterostomy. 
Acknowledgement: Fig. 1 was provided by radiopaedia.org (https://radiopaedia.org/cases/ ureterovaginal-fistula-1).

Competing interests: Dr. Liberman has been an advisor for Boston Scientific and Paladin. The remaining authors report no competing personal or financial conflicts.

This paper has been peer reviewed.

\section{References}

1. Dowling RA, Corriere JN Jr, Sandler CM. latrogenic ureteral injury. J Urol 1986;135:912-5. https://doi.org/10.1016/S0022-5347(17)45921-0

2. St Lezin MA, Stoller ML. Surgical ureteral injuries. Urology 1991;38:497-506. https://doi.org/10.1016/0090-4295(91)80165-4

3. Kitrey ND, Djakovic N, Kuehhas FE, et al. EAU guidelines on urological trauma, 2016. Available at: https://uroweb.org/guideline/urological-trauma. Accessed Feb. 19, 2019.

4. Chou MT, Wang CJ, Lien RC. Prophylactic ureteral catheterization in gynecologic surgery: A 12-year randomized trial in a community hospital. Int Urogynecol J Pelvic Floor Dysfunct 2009;20:689-93. https://doi.org/10.1007/s00192-008-0788-3

5. Sakellariou P, Protopapas AG, Voulgaris $Z$, et al. Management of ureteric injuries during gynecological operations: 10 years' experience. Eur J Obstet Gynecol Reprod Biol 2002;101:179-84. https://doi.org/10.1016/S0301-2115(01)00521-8

6. Redan JA, McCarus SD. Protect the ureters. JSLS 2009;13:139.

7. Morey AF, Brandes S, Dugi DD 3rd et al. Urotrauma: AUA guideline. J Urol 2014;192:327-35. https://doi.org/10.1016/i.juro.2014.05.004

8. Ostrzenski A, Radolinski B, Ostrzenska KM. A review of laparoscopic ureteral injury in pelvic surgery. Obstet Gynecol Surv 2003;58:794-9. https://doi.org/10.1097/01.0GX.0000097781.79401.0B

9. Dandolu V, Mathai E, Chatwani A, et al. Accuracy of cystoscopy in the diagnosis of ureteral injury in benign gynecologic surgery. Int Urogynecol J Pelvic Floor Dysfunct 2003;14:427-31. https://doi.org/10.1007/s00192-003-1095-7

10. Elliott SP, McAninch JW. Ureteral injuries: External and iatrogenic. Urol Clin North Am 2006;33:55-66. https://doi.org/10.1016/i.ucl.2005.11.005

11. Witters $S$, Cornelissen $M$, Vereecken R. latrogenic ureteral injury: Aggressive or conservative treatment. Am J Obstet Gynecol 1986; 155:582-4. https://doi.org/10.1016/0002-9378(86)90283-8

12. Ghali AM, El Malik EM, brahim Al, et al. Ureteric injuries: Diagnosis, management, and outcome. J Trauma 1999;46:150-8. https://doi.org/10.1097/00005373-199901000-00026

13. Cormio L, Battaglia $M$, Traficante $A$, et al. Endourological treatment of ureteric injuries. BJU Int 1993;72:165-8. https://doi.org/10.1111/i.1464-410X.1993.tb00680.x

14. Chang R, Marshall FF. Management of ureteroscopic injuries. J Urol 1987;137:1132-5. https://doi.org/10.1016/S0022-5347(17)44427-2
15. Beckmann CF, Roth RA, Bihrle W 3rd. Dilation of benign ureteral strictures. Radiology 1989;172:437-41. https://doi.org/10.1148/radiology.172.2.2748824

16. Goldfischer ER, Gerber GS. Endoscopic management of ureteral strictures. J Urol 1997;157:770-5. https://doi.org/10.1016/S0022-5347(01)65037-7

17. McQuitty DA, Boone TB, Preminger GM. Lower pole calicostomy for the management of iatrogenic ureteropelvic junction obstruction. J Urol 1995;153:142-5. https://doi.org/10.1097/00005392199501000-00051

18. Barry JM. Surgical atlas transureteroureterostomy. BJU Int 2005;96:195-201. https://doi. org/10.1111/i.1464-410X.2005.05552.x

19. Iwaszko MR, Krambeck AE, Chow GK, et al. Transureteroureterostomy revisited: Long-term surgical outcomes. J Urol 2010;183:1055-9. https://doi.org/10.1016/i.juro.2009.11.031

20. Armatys SA, Mellon MJ, Beck SD, et al. Use of ileum as ureteral replacement in urological reconstruction. J Urol 2009;181:177-81. https://doi.org/10.1016/i.juro.2008.09.019

21. Wein AK, Partin AW, Peters CA. Campbell-Walsh Urology. Philadelphia, PA: Elsevier, p. 1595

22. Lee Z, Keehn AY, Sterling ME, et al. A review of buccal mucosa graft ureteroplasty. Curr Urol Rep 2018;19:23. https://doi.org/10.1007/s1 1934-018-0772-5

23. Meng MV, Freise CE, Stoller ML. Expanded experience with laparoscopic nephrectomy and autotransplantation for severe ureteral injury. J Urol 2003;169:1363-7. https://doi.org/10.1097/01. ju.0000054927.18678.5e

24. Burks FN, Santucci RA. Management of iatrogenic ureteral injury. Ther Adv Urol 2014;6:115-24. https://doi.org/10.1177/1756287214526767

25. Wenske $S$, Olsson CA, Benson MC. Outcomes of distal ureteral reconstruction through reimplantation with psoas hitch, Boari flap, or ureteroneocystostomy for benign or malignant ureteral obstruction or injury. Urology 2013;82:231-6. https://doi.org/10.1016/i.urology.2013.02.046

26. Tracey AT, Eun DD, Stifelman MD, et al. Robotic-assisted laparoscopic repair of ureteral injury: An evidencebased review of techniques and outcomes. Minerva Urol Nefrol 2018;70:231-41.

27. Oppenheimer R, Hinman F Jr. Ureteral regeneration: Contracture vs. hyperplasia of smooth muscle. J Urol 1955;74:476-84. https://doi.org/10.1016/S0022-5347(17)67306-3

28. Toporoff B, Sclafani S, Scalea T, et al. Percutaneous antegrade ureteral stenting as an adjunct for treatment of complicated ureteral injuries. J Trauma 1992;32:534-8. https://doi.org/10.1097/00005373199204000-00019

29. Sharp HT, Adelman MR. Prevention, recognition, and management of urologic injuries during gynecologic surgery. Obstet Gynecol 2016;127:1085-96. https://doi.org/10.1097/A0G.0000000000001425

30. Manodoro $S$, Frigerio $M$, Milani $R$, et al. Tips and tricks for uterosacral ligament suspension: How to avoid ureteral injury. Int Urogynecol J 2018;29:161-3. https://doi.org/10.1007/s00192-017-3497-y

31. Margulies RU, Rogers MA, Morgan DM. Outcomes of transvaginal uterosacral ligament suspension: Systematic review and meta-analysis. Am J Obstet Gynecol 2010;202:124-34. https://doi.org/10.1016/i.ajog.2009.07.052

32. Barbier HM, Smith MZ, Eto CU, et al. Ureteral compromise in laparoscopic vs. vaginal uterosacral ligament suspension: A retrospective cohort. Female Pelvic Med Reconstr Surg 2015;21:363-8. https://doi.org/10.1097/SPV.0000000000000202

Correspondence: Dr. Daniel Liberman, Division of Urology, Department of Surgery, Centre Hospitalier de l'Université de Montréal, Montreal, QC, Canada; danurology@gmail.com 